\title{
Acceso y apropiación del agua en comunidades rurales pobres de Argentina central. Transformaciones y conflictos
}

\section{Access and appropriation of water in poor rural communities in central Argentina. Transformations and conflicts}

\author{
DANIEl M. CÁCERES* \\ Pablo Rodríguez-Bilella**
}

\begin{abstract}
Based upon a case study in central Argentina, this papermakes conceptualizations in order to understand the strategies to appropriate rural water, furthermore it discusses how recent socio-productive changes affect this appropriation and, finally, it examines the possible social consequences. The results suggest that the expansion of agrarian capitalism undermines the autonomy of poor peasants and inhabitants to access water for human consumption or production. This reinforces the subordinated position of the rural poor and the structural inequality of these territories, increasing their vulnerability before clientelistic relationships. On the other hand, capitalized producers are more successful in the appropriation of rural water.
\end{abstract}

Keywords: rural development, peasants, water access, water appropriation, social conflicts.

\section{Resumen}

Basado en un estudio de caso en Argentina central, esta investigación formula conceptualizaciones tendientes a comprender las estrategias de apropiación del agua rural; asimismo, analiza cómo las recientes transformaciones socioproductivas influyen en su apropiación y, finalmente, discute sus probables consecuencias sociales. Los resultados sugieren que el avance de la expansión del capitalismo agrario debilita la autonomía de los campesinos y pobladores pobres para acceder al agua con fines de consumo humano o productivo. Esto consolida la posición subordinada de los pobres rurales y la inequidad estructural de estos territorios, aumentando su vulnerabilidad ante prácticas clientelares. Por su parte, los productores capitalizados son más exitosos al apropiarse del agua rural.

Palabras clave: desarrollo rural, campesinos, acceso al agua, apropiación del agua, conflictos sociales.

* Consejo Nacional de Investigaciones Científicas y Técnicas y Universidad Nacional de Córdoba.Correo-e: dcaceres@agro.unc.edu.ar

** Consejo Nacional de Investigaciones Científicas y Técnicas y Universidad Nacional de San Juan. Correo-e: pablo67@gmail.com 


\section{Introducción}

Los cambios y transformaciones producidos en los ecosistemas en las últimas décadas han contribuido al logro de beneficios considerables para el bienestar humano. Sin embargo, en muchos casos esto ha generado importantes costos ambientales y sociales, como la pérdida de servicios ecosistémicos claves para la sociedad, el aumento de la pobreza y el deterioro de las condiciones de vida para los grupos sociales más vulnerables (MA, 2003; 2005).

El agua dulce es uno de los servicios ecosistémicos claves para satisfacer las necesidades básicas de las sociedades, ésta no sólo es esencial para el consumo humano, sino también desempeña un rol en la producción de otros servicios ecosistémicos de aprovisionamiento, tales como comida, vestimenta, abrigo, etcétera, así como en el ámbito de servicio cultural o intangible para las culturas.

Desde distintas perspectivas, escalas y contextos espaciales e históricos el agua es un factor clave para el desarrollo humano. Para las poblaciones pobres el acceso al vital líquido constituye una premisa fundamental para garantizar una calidad de vida digna, por tal motivo, la vinculación entre pobreza y manejo del agua constituye uno de los focos de atención de los gobiernos y de los responsables en formular políticas sociales. En tal sentido, entre los Objetivos de Desarrollo del Milenio se presenta una meta específica al respecto la cual consiste en que para el año 2015 se reduzca a la mitad la proporción de la población mundial sin acceso sostenible al agua potable segura y al saneamiento (MA, 2003).

En los territorios rurales donde el acceso al agua se relaciona no sólo con las necesidades de consumo humano sino también con cuestiones productivas, el vínculo entre acceso al agua y pobreza adquiere gran relevancia (Hodgson, 2007; Poverty-Environment Partnership, 2006). Es precisamente en los espacios rurales donde la competencia por el agua se ha intensificado, ya que el uso humano directo compite de un modo creciente con la producción agropecuaria intensiva o industrial como la minería a cielo abierto (Svampa y Antonelli, 2009). Pero no es la existencia de distintos usos como el consumo humano o productivo lo que fomenta las disputas y conflictos, sino los cambios que se han producido durante los últimos años en la actividad productiva y el interés del capital por expandir su acción hacia espacios anteriormente menos explotados.

En el ámbito agropecuario estos cambios se reflejan en la intensificación de la producción ganadera y la expansión de la agricultura industrial hacia áreas anteriormente ocupadas por ecosistemas nativos donde dominaba la producción campesina (Cáceres et al., 2010; Silvetti et al., 2013). Estas transformaciones están impactando negativamente a los pobres 
rurales, quienes a menudo tienen restringido el acceso al agua para uso humano o productivo (Montańa, 2013). Es necesario destacar que dicho acceso no depende solamente de sus derechos, sino también de la naturaleza y nivel de (in)equidad política y económica propia de las instituciones a través de las cuales se registran, sancionan y refuerzan los derechos al agua, así como por las oportunidades económicas y tecnológicas a las que acceden los distintos actores sociales (DIss, 2006).

El acceso al agua es a menudo entendido como el resultado de relaciones sociales (Bruns y Meinzen-Dick, 2005) que en gran medida dependen de las relaciones de poder existentes entre los actores sociales (Cleaver y Franks, 2007) que operan en un determinado contexto espacial e histórico (Meinzen-Dick y Nkonya, 2005). Si bien este constituye un aspecto clave a considerar cuando se analiza el acceso al agua por parte de los pobres rurales, en esta investigación se enfoca el problema desde una perspectiva interdisciplinaria más amplia.

Partiendo de los conceptos de agua verde y azul (ver próxima sección) y con base en un estudio de caso situado en el oeste de la Provincia de Córdoba, Argentina, el presente artículo se propone: (i) formular nuevas conceptualizaciones que permitan comprender mejor las estrategias de apropiación del agua por parte de distintos actores sociales; (ii) analizar cuáles han sido las principales transformaciones socioproductivas observadas durante las últimas décadas que influyen directa o indirectamente en la apropiación del agua, y (iii) analizar las probables consecuencias sociales que tendrían estos cambios en el futuro próximo.

Una revisión de la bibliografía reciente sobre el tema permite observar que se han realizado importantes esfuerzos por comprender los distintos roles que cumple el agua en el mantenimiento de la vida del planeta. Así, se han catalogado los distintos tipos de agua que componen la reserva hídrica global, a fin de poder estudiar mejor los principales flujos y su relevancia para la sociedad.

La clasificación que ha alcanzado mayor difusión es la que distingue agua azul de agua verde (Postel et al., 1996; Falkenmark, 1997). Con un énfasis fundamentalmente físico-biológico se describe como agua azul a aquella que se encuentra en estado líquido, ya sea en la superficie (ríos y lagos) o almacenada en el subsuelo (acuíferos). Es el agua comúnmente asociada a fuentes de abastecimiento para riego o consumo humano. El escurrimiento superficial que se produce luego de las lluvias también forma parte de esta categoría. El agua verde, en cambio, corresponde a la que se encuentra en el área no saturada del suelo, más la transformada en vapor de agua a través de los procesos de evapotranspiración. Se considera agua verde tanto a la transpirada por los vegetales, como a la que está 
siendo evaporada del suelo o de aguas superficiales (Rockström et al., 2009; D'Odorico et al., 2010).

La lluvia es una forma indiferenciada de agua dulce pero puede convertirse en agua azul o verde según pase a formar parte de los cursos y reservorios superficiales o subterráneos, o se integre al flujo de vapor de agua atmosférico vía evapotranspiración. Debido a que la mayor parte de la producción agropecuaria ocurre en áreas de secano, ésta utiliza fundamentalmente el agua verde. La agricultura bajo riego se complementa con agua azul (Hoff et al., 2010).

A pesar de que el agua azul es la más fácil de identificar por la sociedad, desde el punto de vista cuantitativo es la menos importante y representa sólo la tercera parte del agua dulce global (Falkenmark y Rockström, 2006; Hoff et al., 2010). Existen trade-offs entre agua azul y verde, ya que como el volumen de agua presente en el planeta es finito, si aumenta el volumen de una necesariamente disminuye el volumen de la otra; es decir, no se pueden maximizar los dos tipos de agua al mismo tiempo.

Este enfoque es un aporte importante para la comprensión de las dinámicas hídricas no sólo porque ha permitido identificar con mayor claridad las características y particularidades del ciclo hidrológico, sino también porque permitió identificar un tipo de agua vital para los ecosistemas, es decir, la verde, que resulta altamente importante para la sociedad. Reconocer la importancia del agua verde genera un nuevo espacio de análisis donde se relativiza la importancia del agua azul y las acciones relacionadas con su aprovechamiento (construcción de represas e infraestructura de riego), dando paso a estrategias que ponen el acento en el manejo del agua verde (Hoff et al., 2010; Rockström et al., 2009).

Partiendo de una descripción del área de estudio y de los principales actores en conflicto por el agua, el artículo propone los conceptos de agua apropiada con y sin mediación institucional, como una forma de incluir las relaciones de poder vinculadas a las disputas por el líquido. Luego se analizan las transformaciones socioproductivas ocurridas en la región durante los últimos años y se discuten las estrategias de apropiación del agua que llevan adelante los principales actores sociales tanto en áreas rurales como urbanas. Finalmente, se discuten las implicancias que estos cambios tienen para actores sociales con distinto poder relativo y se especula sobre posibles escenarios futuros.

\section{Metodología}

La investigación fue realizada en el marco de un proyecto interdisciplinario que apuntó a integrar a profesionales de las ciencias sociales y biológicas. El trabajo de campo fue de tipo etnográfico (Ameigeiras, 2007) 
en el cual se realizaron múltiples y recurrentes entrevistas de fondo a informantes calificados y a actores sociales de distintas categorías (campesinos, productores capitalizados, funcionarios, etc.). La participación de los investigadores en eventos locales (actos políticos, asambleas de campesinos, actividades escolares, etc.) permitió complementar y enriquecer el material obtenido a través de las entrevistas.

La información fue registrada en distintas plataformas (libretas de campo y grabaciones de audio y video, principalmente), y volcada posteriormente en un paquete informático para el análisis cualitativo de la información denominado Atlas.ti. El proceso de análisis fue inductivo, desarrollando conceptos y comprensiones a partir de los datos al abordar la información del escenario desde una perspectiva holística, lo cual dio cabida a la multiplicidad de perspectivas del contexto abordado (Taylor y Bogdan, 2000).

\section{El área de estudio}

\subsection{Caracterización ecológica y socioeconómica}

La investigación tuvo lugar en la localidad de Chancaní y parajes rurales vecinos como el Departamento Pocho, al oeste de la Provincia de Córdoba, Argentina. El clima es subtropical seco, con lluvias estivales de 500 $\mathrm{mm}$ anuales (Cabido et al., 1994) y un déficit hídrico de entre 500 y $800 \mathrm{~mm}$ (Carranza y Ledesma, 2005). Desde el punto de vista topográfico es una planicie ubicada entre 300 y $400 \mathrm{msnm}$, con ondulaciones suaves y pendientes inferiores a 1 por ciento. Los suelos son francos, permeables y de escaso desarrollo, o franco-limosos con mayor capacidad de retención hídrica (Cabido et al., 1994). El área corresponde al distrito fitogeográfico del Distrito chaqueño occidental, cuya vegetación potencial es un bosque xerófilo dominado por quebracho blanco (Aspidosperma quebracho-blanco) y algarrobo (Prosopis spp) (Cabrera, 1976).

En la actualidad, se observa un mosaico de situaciones ecológicas que responden a distintos usos históricos del suelo. Conti (2011) describe seis configuraciones biológicas que van desde el bosque primario casi no intervenido, hasta áreas con un alto nivel de intervención actualmente ocupadas por agricultura industrial bajo riego. Entre estos dos extremos identifican cuatro situaciones sujetas a distintas intensidades de intervención y manejo ganadero.

En términos productivos, el área es fundamentalmente ganadera (Silvetti, 2010) y forma parte de la zona homogénea árida de Traslasierra de ganadería extensiva (Ghida-Daza y Sánchez, 2009). La carga animal es de 10 equivalente a vaca/ha (Bocco et al., 2007). Estudios realizados por 
el Instituto Nacional de Estadísticas y Censos (INDEC) advierten que vacunos y caprinos son los principales rubros ganaderos del Departamento Pocho: 33,257 vacunos y 18,661 caprinos (INDEC, 2003). La agricultura intensiva bajo riego es una actividad emergente de marcada expansión durante los últimos años. De un total de 436 explotaciones agropecuarias, sólo 32 (7\%) superan las 1,000 hectáreas (promedio 3,020 ha). No obstante, concentran 55\% de la tierra (INDEC, 2003). Los campesinos se dedican fundamentalmente a la capricultura, mientras que los medianos y grandes productores a la ganadería vacuna o a la agricultura bajo riego (Tapella, 2011).

El Departamento Pocho es netamente rural sin centros urbanos importantes; su población puede caracterizarse como rural, dispersa y con una densidad muy baja ( 1.6 habitantes $\left./ \mathrm{km}^{2}\right)$. Desde el punto de vista económico es un área deprimida y pobre, pues $40.8 \%$ de los habitantes tienen al menos una necesidad básica insatisfecha. Esta cifra contrasta con los valores de la Provincia de Córdoba, donde sólo 13\% de la población se encuentra en esta situación (INDEC, 2001).

\subsection{Transformaciones socioeconómicas}

Durante las últimas décadas ocurrieron importantes cambios socioproductivos, pues desde 1960 se produce una progresiva concentración de la tierra que ha llevado el tamaño promedio de las explotaciones de 200 a 400 hectáreas, correspondiendo la mayor pérdida a las explotaciones de menos de 200 ha (Silvetti, 2010; Cáceres, 2014). La desaparición de explotaciones campesinas y la expansión de la actividad empresarial favorecen la bovinización de la ganadería de la región. Entre 1908 y 2002 la cantidad de caprinos se redujo a la mitad, pasando de 35,687 a 18,511 cabras (Ferrer, 2007). En cambio, las existencias bovinas que habían estado estabilizadas durante el siglo pasado, alrededor de las 30,000 cabezas (Silvetti, 2010), se duplican durante los últimos años para ubicarse en torno a las 63,000 cabezas (Calvo et al., 2008).

La cantidad de habitantes en el Departamento Pocho prácticamente no muestra cambios durante los últimos 100 años, ya que pasa de 6,266 (en 1914) a 5,147 (en 2008); esto sugiere que dicha demarcación se ha comportado como un expulsor neto de población hacia otras regiones. Paralelamente, los que aún permanecen están abandonando su residencia rural para concentrarse en municipios y comunas. Este proceso de urbanización se observa con claridad en la localidad de Chancaní, que pasó de tener 129 habitantes en 1991 a 520 en 2008 (Silvetti, 2010). En la actualidad, su población es de 700 personas (Tapella, 2011), lo que muestra un crecimiento poblacional de $542 \%$ en sólo 20 años. 


\subsection{Actores sociales en conflicto}

En el territorio en estudio se destacan dos actores sociales que disputan similares recursos y servicios ecosistémicos: los pobres rurales y los productores capitalizados. ${ }^{1}$ Escobal y Ponce (2000) realizan una pormenorizada caracterización de los pobres rurales, quienes constituyen una categoría muy heterogénea y ampliamente representada en Latinoamérica. Además de su residencia rural, este actor social no satisface todas sus necesidades básicas, especialmente en salud y educación, tienen menor acceso a la infraestructura y servicios públicos, y a menudo pertenecen a grupos indígenas, y como consecuencia de su posición subordinada muestran una mayor vulnerabilidad social y dependencia del Estado.

Los campesinos constituyen un subgrupo de esta categoría. Las unidades campesinas pueden ser entendidas como un ámbito de actividad múltiple que no se restringe exclusivamente al campo productivo. La estructura y funcionamiento de este tipo de sistemas presenta una mayor complejidad funcional, ya que además de producir bienes de mercado, cumplen también la función de vivienda familiar única y a menudo constituye la principal fuente de provisión de alimentos para el grupo doméstico. Por lo tanto, en este tipo de explotaciones las actividades productivas están indisolublemente unidas a la esfera doméstica (Schejtman, 1975). Este es el motivo por el cual con frecuencia se refiere a las unidades campesinas como unidades de producción-vivienda-consumo.

Cáceres (2003) analiza cinco aspectos distintivos de la producción campesina: (i) uso predominante de mano de obra familiar, (ii) control formal del proceso de producción, (iii) escasa disponibilidad de recursos productivos, (iv) posición subordinada (social, económica y política), y (v) dificultades estructurales para acumular capital. Así, la heterogeneidad, el dinamismo y el cambio son atributos destacados de las sociedades campesinas.

La comprensión de la estructura y dinámica de las sociedades campesinas sólo es posible si la complejidad de sus estrategias de reproducción social y la forma en que se articulan con otros actores sociales se analizan de una manera integral. No es posible comprender totalmente al campesinado en la medida en que no se comprenden las condiciones históricas en las que tuvo lugar su emergencia y desarrollo (Cáceres, 2003).

Para los productores capitalizados, el centro de su operación económica radica en la maximización de la tasa de ganancia, mientras que la estructura y organización de sus unidades de producción busca optimizar

\footnotetext{
${ }^{1}$ Existen otros actores sociales que directa o indirectamente ejercen distintos tipos de influencias sobre los procesos que ocurren en el territorio en estudio, por ejemplo, el Estado a través de las políticas públicas.
} 
la combinación de recursos productivos a fin de alcanzar el objetivo seńalado. El uso de mano de obra contratada es una de las características centrales de esta categoría productiva, ya que trabajan casi exclusivamente para el mercado y su generación de bienes se concentra en torno a aquellos rubros con mayor rentabilidad potencial.

Desde el punto de vista productivo, siguen los lineamientos generales que propone la agricultura industrial, es decir, los planteos agrícolas se apoyan en el paquete tecnológico como siembra directa, semillas transgénicas y agroquímicos, mientras los ganaderos se basan en el reemplazo de la vegetación natural por forrajeras megatérmicas y la realización de mejoras de infraestructura que optimicen la productividad vacuna (Cáceres et al., 2011). Este abordaje empresarial de la producción agropecuaria se ha difundido notablemente en Latinoamérica durante los últimos años, siendo Argentina uno de los países en los que la expansión ha sido particularmente intensa.

Este modelo productivo se vincula con lo que en diversos ámbitos académicos se describe como la expansión de los agronegocios (Gudynas, 2010; Cáceres, 2014). El rápido desarrollo de este nuevo enfoque económico trasciende largamente la esfera productiva y ha reconfigurado fronteras naturales, sociales y políticas. Sin embargo, este proceso de cambio no se explica solamente por razones tecnológicas, ya que como señalan Gras y Bidaseca (2010), también fue necesaria una profunda reestructuración del Estado, de los vínculos entre el capital, el trabajo y la tierra, así como de la articulación del sector agropecuario con otros sectores de la economía y con el mercado internacional. Así, este abordaje representa una nueva manera de entender y practicar la actividad agropecuaria que genera nuevos y profundos impactos ecosociales (Gras, 2009).

\subsection{El agua en el área de estudio}

La distribución de aguas superficiales es bastante irregular en el territorio provincial. Según el Plan de Gestión de Recursos Hídricos de la Provincia de Córdoba, el área de estudio se localiza en la Zona de Cuencas de Ríos de Traslasierra (Reyna et al., 2006). Debido a las escasas precipitaciones, las altas temperaturas y la permeabilidad de los sedimentos superficiales, las planicies de la pendiente occidental de la provincia se caracterizan por la pobreza de aguas superficiales corrientes o estancadas (Vásquez et al., 1979). En el área de estudio las aguas superficiales son sumamente escasas y se limitan al río La Mermela que baja de las Sierras de Pocho. A la altura de Chancaní el curso del río está seco ya que es captado en el piedemonte para alimentar dos represas públicas que abas- 
tecen de agua para uso humano a Chancaní, y para uso humano y productivo en parajes vecinos.

En algunos sectores también existe agua subterránea. Siguiendo la clasificación nacional, el área de estudio se incluye en la región 7 correspondiente a las Sierras Pampeanas y sus Valles (Auge et al., 2006); sin embargo, a una escala menor y según una clasificación provincial se encuentra en la Cuenca de las Salinas Grandes (Vásquez et al., 1979), pero son escasos los trabajos científicos que analizan la hidrogeología de la región. Para regiones vecinas al área de estudio que guardan ciertas similitudes ecológico-productivas, destacan las investigaciones de Jobbagy et al. (2008) y Santoni et al. (2010), quienes analizan cómo el reemplazo del bosque xerófilo chaqueño por cultivos anuales de secano afecta el ciclo hidrológico y la salinidad de aguas y suelos.

\section{Producción y apropiación del agua}

El agua es a menudo un bien escaso y su acceso se relaciona con los procesos de producción del agua por parte de los ecosistemas y de las relaciones de poder propias de cada momento histórico y de cada sociedad en particular. No obstante, la mayoría de los estudios sobre el agua se focalizan en su captación, almacenamiento y administración, a fin de garantizar un uso eficiente y racional (Bruns y Meinzen-Dick, 2005). Por otro lado, no abundan los trabajos que analizan sus principales tipos, flujos y estados en los ecosistemas, así como los vínculos que existen entre su apropiación y las estructuras económicas y políticas dominantes; tampoco se valoran suficientemente los impactos que las sociedades causan sobre los ecosistemas, transformando sus procesos básicos y afectando, con estos cambios, el funcionamiento ecosistémico de los principales flujos y estados del agua, lo que condiciona, su producción y posterior apropiación.

Tomando como base la terminología precedente que enfatiza aspectos físico-biológicos, a continuación se presentan nuevas conceptualizaciones que se enfocan en aspectos fundamentalmente sociales y que se refieren a las diferencias que existen entre los modos de apropiación del agua para uso humano o productivo por parte de los actores sociales, se identifica específicamente dos formas según exista o no algún tipo de mediación institucional en dicho proceso.

\subsection{Apropiación del agua y meditación institucional}

El agua apropiada sin mediación institucional (en adelante, agua ASMI) es aquella procesada por los ecosistemas locales, utilizada para uso humano 
o productivo, y que para su apropiación no depende de acuerdos sociales específicos con terceros y de ningún tipo de mediación institucional (formal o informal). Queda incluida dentro de esta categoría toda el agua verde y parte del agua azul, es decir, aquella que se infiltra en el suelo, la contenida en las plantas y la que es posteriormente evapotranspirada y transformada en vapor atmosférico, además de la porción de agua azul (superficial o subterránea) que es apropiada en forma privada y a pequeña escala por los usuarios finales. Queda fuera de esta categoría el agua freática utilizada para riego de cultivos o pasturas a escala comercial, pues forma parte de otra categoría (ver tabla 1).

En el área de estudio, el agua ASMI incluye al agua contenida en la biomasa de los ecosistemas y que está siendo transformada a través de los distintos procesos físico-biológicos. A partir de ellos se producen el forraje necesario para la producción ganadera, parte del agua utilizada para producir granos generados por la actividad agrícola (más precisamente, la diferencia entre la evapotranspiración de los cultivos y el riego requerido para su producción), y muchos otros servicios ecosistémicos de los que dependen los distintos actores sociales.

Para apropiarse de este tipo de agua, los productores desarrollan estrategias específicas tales como el manejo de pasturas naturales, el uso de determinadas técnicas agrícolas o la recolección de leña y hierbas medicinales; también disponen de estrategias tendientes a apropiarse, al menos, de parte del agua azul que requieren para desarrollar sus actividades. Aquí se incluyen estrategias destinadas a la captación de agua para uso humano y productivo, tales como el cavado de pozos para la extracción de agua con balde o molino, o la cosecha del agua de escorrentía en pequeñas represas.

Por otro lado, el agua apropiada con mediación institucional (en adelante, agua ACMI) es utilizada para uso humano o productivo, no necesariamente procesada por los ecosistemas locales y que para su apropiación requiere de acuerdos sociales específicos con terceros o de algún tipo de mediación institucional (formal o informal); es decir, requiere no sólo de acuerdos con instituciones formalmente organizadas (Appendini y Nuijten, 2002) sino con un amplio rango de organizaciones que se norman bajo políticas y procesos que influyen en las opciones de apropiación de los recursos, en este caso, el agua (Messer y Townsley, 2003).

Así, la mediación institucional está sujeta a las redes sociales y organizaciones de pertenencia, así como a las diversas reglas y normas que determinan el acceso a los recursos (De Herdt et al., 2004). Esta categoría incluye fundamentalmente agua azul, específicamente aquella que para ser apropiada por parte de los usuarios requiere de la intervención de arreglos sociales o de instituciones públicas o privadas formales o informales que norman y regulan su captación, almacenamiento o distribución, 
por ejemplo, los consorcios de riego regulados por el Estado, comisiones de regantes, o arreglos vecinales. Aunque tal vez menos frecuente, el agua ACMI puede también incluir agua verde (por ejemplo, el pastoreo de tierras de terceros).

En el área de estudio, el agua ACMI incluye a la contenida en las represas públicas de Chancaní que administra la Comisión de Agua Local, la proveniente de las perforaciones para consumo humano que maneja la municipalidad y el agua freática utilizada para regar cultivos agrícolas comerciales. Las dos primeras están reguladas por instituciones que operan y deciden a nivel local, y la última depende de regulaciones e instancias de decisión provinciales. También se considera agua ACMI la que se obtiene a partir de arreglos informales -menos visibles, pero igualmente importantes a escala local-, mismos que permiten a productores que no disponen de suficiente agua azul, tener acceso al agua de terceros ya sea para consumo humano o animal. Asimismo, campesinos que tienen poca tierra o que no disponen de suficiente forraje pueden negociar el acceso de sus animales a campos de terceros.

A diferencia de lo que ocurre con la apropiación del agua ASMI, los actores sociales despliegan aquí una serie de estrategias que trascienden la esfera individual para ubicarse de lleno en el plano social, institucional y político. A modo de síntesis, se presenta a continuación una comparación de los tipos de agua analizados en esta investigación (tabla 1).

Tabla 1

Principales características del agua azul, verde, apropiada sin mediación institucional (ASMI) y apropiada con mediación institucional (ACMI)

\begin{tabular}{|c|c|c|c|}
\hline \multicolumn{4}{|c|}{ Tipos de Agua } \\
\hline Azul & Verde & $A S M I$ & $A C M I$ \\
\hline $\begin{array}{l}\text { agua líquida } \\
\text { (agua de esco- } \\
\text { rrentía, ríos, } \\
\text { represas, acuí- } \\
\text { feros). }\end{array}$ & $\begin{array}{l}\text { agua no líquida } \\
\text { (agua edáfica, } \\
\text { agua evapo- } \\
\text { transpirada). }\end{array}$ & $\begin{array}{l}\text { agua verde y azul apro- } \\
\text { piada sin participación } \\
\text { institucional } \\
\text { (cosecha de agua de } \\
\text { escorrentía, pozos de } \\
\text { balde, agua en biomasa } \\
\text { de apropiación } \\
\text { privada). }\end{array}$ & $\begin{array}{l}\text { agua verde y azul apro- } \\
\text { piada con mediación } \\
\text { institucional } \\
\text { (agua freática para rie- } \\
\text { go, agua pública, con- } \\
\text { sorcios, acuerdos de uso } \\
\text { de agua o pasturas de } \\
\text { terceros). }\end{array}$ \\
\hline
\end{tabular}

Fuente: elaboración propia. 


\subsection{Transformaciones productivas y sociales}

Como consecuencia de un conjunto de factores ecológicos, económicos, tecnológicos y políticos se está produciendo en Argentina un fuerte avance de la agricultura y ganadería empresarial en territorios anteriormente ocupados por bosques nativos (Trigo y Cap, 2003; Cabido et al., 2005; Zak et al., 2008), en donde predominaba la producción campesina centrada en la cría extensiva de caprinos y bovinos (Cáceres et al., 2010; 2011).

Este proceso también se observa en el área de estudio (Silvetti, 2010; Tapella, 2011). La agricultura intensiva de cultivos anuales y la ganadería bovina empresarial son las principales actividades que se están expandiendo. En el caso de la agricultura, luego del desmonte, se siembra papa, maíz, trigo o soja, utilizando las técnicas propias de la agricultura industrial. Debido al elevado déficit hídrico, se realizan riegos complementarios utilizando riego gravitacional con agua del Dique La Viña, o por aspersión, usando agua subterránea.

En los planteos ganaderos se realiza desmonte selectivo o total y se implantan pasturas exóticas; esta propuesta tecnológica viene acompańada por una importante inversión en infraestructura, en particular, la construcción de alambrados perimetrales que impiden la entrada de animales de terceros a los campos. Si bien esta es un área marginal para la producción ganadera, la expansión se produce como consecuencia del desplazamiento de la ganadería de las áreas pamperas, las que hoy se dedican a actividades más rentables, fundamentalmente al cultivo de soja (Silvetti, 2010).

El proceso descrito está generando importantes impactos ecológicos y sociales, ya que no sólo modifica el paisaje sino también el escenario social y la relación de fuerzas entre actores. Los campesinos han sido fuertemente afectados por el proceso, debido a que la expansión empresarial ocurrió a expensas de territorios que históricamente ellos utilizaban. En una región en la que muy pocos títulos de propiedad están saneados y que hasta hace muy poco era considerada como de escaso interés productivo, los campesinos utilizaban con cierta libertad el agua y las tierras de pastoreo. En los casos en los que disponían de poca tierra, se negociaba con los vecinos a fin de que les permitieran pastorear sus animales, o bien, se utilizaban campos de productores ausentistas. Como bien señala Silvetti (2010), la mayor presencia empresarial en la zona y la prohibición del acceso de los animales de los campesinos a los campos de terceros deja al descubierto las inequidades históricas en la distribución de la tierra.

Esto impacta negativamente a los campesinos ya que al tener dificultades para acceder al agua y a las tierras de pastoreo, en muchos casos, han dejado de ser productores y emigran a los centros urbanos. El proce- 
so de abandono del medio rural es reforzado a partir de la incidencia de dos aspectos vinculados con la esfera política. Por un lado, la desatención que por décadas el Estado ha tenido con campesinos y pobladores pobres de áreas rurales, sumado a la deficiente infraestructura en estas regiones -caminos, educación, salud, acceso a mercados, comunicaciones, etcétera-, ha generado procesos crónicos de descapitalización económica y social y, por tanto, una condición crítica a las sociedades campesinas.

Por otro lado, los centros urbanos se comportan como fuerzas que traccionan los procesos de descampesinización: las malas condiciones existentes en el campo, las escasas posibilidades de proyección socioeconómica y el deseo por tener un mejor acceso a los servicios básicos conspiran en contra del mantenimiento de su residencia rural. Sin embargo, este proceso es revertido por políticos locales, quienes les ofrecen beneficios para que regresen a los pueblos, tales como ladrillos para construir sus casas, alimentos, medicinas, o empleos temporales, lo que luego genera dependencias clientelares (Cáceres et al., 2010).

Finalmente, cabe destacar que las características estructurales de estas transformaciones no son producto de situaciones que ocurren a escala regional, sino que guardan directa relación con el modelo agroalimentario global y el estilo de desarrollo dominante en los países latinoamericanos (Rubio, 2007; Cáceres et al., 2011). Procesos similares de cambio de uso de la tierra -con sus consecuencias ecológicas y sociales- están ocurriendo en distintos lugares de Argentina (Van Dam, 2003; Cardona, 2006; Román y González, 2006; Zarrilli, 2007; Britos y Barchuk, 2008; Pérez-Carrera et al., 2008; Aizen et al., 2009) y también en otros países de Sudamérica (Palau y Kretschmer, 2004; Palau-Viladesau, 2005; Robin, 2008; Bravo, 2010; Centurión-Mereles, 2010; Domínguez y Sabatino, 2010).

\section{Estrategias de apropiación del agua en el área rural}

\subsection{En el área rural}

Los productores del área de estudio han desarrollado un conjunto de mecanismos destinados a lograr el acceso al agua ASMI y al agua ACMI que necesitan para desarrollar sus estrategias productivas y satisfacer sus necesidades básicas. Para aprovechar el agua ASMI utilizan dos estrategias. A continuación se describen primero las relacionadas con el aprovechamiento del agua azul.

En el área de estudio existen 145 pequeńas represas prediales, así que la primera estrategia para el aprovechamiento del agua es la selección cuidadosa del lugar de construcción que favorezca la captación del agua de escorrentía de tal manera que los productores aprovechen los desni- 
veles naturales y, de ser necesario, construyan bordos u hondonadas a fin de canalizarla mejor; la escasa vegetación y la compactación del suelo, propias de las áreas próximas a las represas, contribuyen también a dicha captación. Asimismo, el cercado y desbarrado periódico son mecanismos claves para tal propósito. Otra estrategia de apropiación de agua azul es el cavado de pozos (15 a $40 \mathrm{~m}$ ) de donde extraen el agua a balde o con molino.

La principal estrategia de aprovechamiento con respecto al agua ASMI verde es el pastoreo, para lo que se utilizan un conjunto de técnicas destinadas a aprovechar de la mejor manera posible el forraje. Cabe mencionar que, en el caso de los campesinos, el manejo es extensivo y se basa en el aprovechamiento integral del bosque nativo. Debido a que se crían principalmente cabras se pueden aprovechar muy bien ambientes de muy diferente condición ecológica, en particular, las áreas con poco pasto y donde dominan los arbustos bajos y espinosos. También se desarrollan otras estrategias de aprovechamiento del agua verde no vinculadas con la ganadería, pero importantes para su reproducción social como la recolección de leña, producción de carbón, obtención de postes y recolección de hierbas medicinales.

Los productores capitalizados ganaderos orientan su estrategia al aprovechamiento de las gramíneas forrajeras y, si las condiciones se lo permiten, implantan pasturas exóticas megatérmicas como el buffel grass. Debido a que se crían vacas, no se prefieren los ambientes sombreados que limitan el crecimiento de los pastos ni tampoco aquellos en los que dominan los arbustos bajos y espinosos que dificultan el desplazamiento de los animales. En consecuencia, se presenta una proclividad a disminuir o eliminar el estrato leñoso utilizando técnicas de desmonte selectivo o el rolado de arbustos. Los grandes productores que realizan agricultura bajo riego también utilizan agua verde ya que el crecimiento de los cultivos depende, en parte, del agua proveniente de las precipitaciones.

Con respecto al agua ACMI, también se observan diferencias según sean las características de los productores y el tipo de agua considerada. Varias son las estrategias que implementan para apropiarse del agua ACMI azul, entre las que se encuentran la acumulación de agua en las represas prediales existentes en la zona, ya que estas no almacenan sólo agua ASMI. Debido a que las precipitaciones se concentran en el verano, los productores dependen fuertemente del agua ACMI y obtenerla implica mantener en buen estado las represas y también las acequias de tierra que trasladan el agua proveniente de las represas públicas de Chancaní. Pero su apropiación no depende sólo de cuestiones técnicas vinculadas al mantenimiento de represas y acequias. El punto crucial se sitúa en la esfera sociopolítica, 
ya que los productores deben desarrollar estrategias específicas que les permitan acceder a un recurso vital claramente insuficiente.

La Junta Promotora de Agua de Riego de Chancaní (en adelante, Junta de Aguas) es el organismo descentralizado que regula el uso del agua captada en las represas públicas, el cual no tiene un reglamento escrito que norme su funcionamiento y que presente de forma clara y transparente los criterios de asignación del agua. La Comisión Directiva se renueva periódicamente y, a pesar de que los cargos son ad-honorem, existe un gran interés por integrarla ya que representa una posición de poder importante (Rodríguez-Bilella, 2011). El Código de Aguas para la Provincia de Córdoba (ley 5589), conjuntamente con la Ley Orgánica de la Dirección de Agua y Saneamiento (ley 8548) y la ley 6604 referida a la creación de Consorcios de Usuarios, proporcionan el marco legal general a partir del cual opera la Junta de Aguas.

Otra estrategia de apropiación de agua azul es la que se refiere al aprovechamiento de agua subterránea para riego. Los grandes productores agrícolas realizan perforaciones (a menudo de más de $100 \mathrm{~m}$ ) que les permiten alcanzar napas profundas con capacidad de entregar agua de calidad adecuada y en cantidad suficiente para abastecer los poderosos equipos de riego de pivote central. Según Tapella (2011) la cantidad de agua consumida es importante, ya que existen unas 260 perforaciones que riegan parcelas circulares de hasta 120 ha cada una. Debido a la elevada evapotranspiración se requiere un aporte de riego de unos 500 $\mathrm{mm} /$ ciclo productivo o de $1.000 \mathrm{~mm}$ /año en manejos de doble cultivo.

A diferencia del agua administrada por la Junta de Aguas a la que en mayor o menor medida acceden distintos tipos de productores, el agua ACMI subterránea es aprovechada sólo por los grandes productores. Cabe destacar que, según el Código de Aguas, los pozos explotados a balde o con molinos propulsados a viento no están sujetos al control y supervisión de ningún organismo público o privado y, por lo tanto, se incluyen dentro de la categoría de agua ASMI. En cambio, existen normas que regulan su uso como las leyes arriba referidas, cuando ésta es extraída con motores y bombas. Sin embargo, los controles de los organismos competentes casi no existen y en la práctica se produce una explotación cuasi minera del agua subterránea.

En contraste, existen estrategias de apropiación de agua ACMI que implementan sólo los campesinos que no disponen de suficiente tierra y agua y, por lo tanto, deben negociar acuerdos con productores vecinos para que sus animales puedan acceder a estos recursos básicos. A menudo este acceso está acompañado por alguna retribución por parte del beneficiario, a modo de reconocimiento por la ayuda recibida, tales como colaboración en tareas rurales, mantenimiento de instalaciones, etcétera. 
Los acuerdos son el resultado de negociaciones permanentes y muchas veces responden a prácticas culturales consuetudinarias, desarrolladas y aceptadas por las sociedades locales como estrategias de ayuda mutua y de redistribución de recursos. Estos mecanismos permiten a los campesinos apropiarse de parte del agua ACMI azul y verde disponibles en el territorio.

Con respecto al agua destinada a consumo humano, la situación es bastante heterogénea pues los productores capitalizados generalmente disponen de fuentes permanentes de agua de buena calidad proveniente de pozos o perforaciones. Los campesinos en algunos casos tienen acceso al agua proveniente de pozos de balde, de lo contrario dependen del agua que vende la municipalidad y distribuye con camiones cisterna. En unos pocos parajes rurales existen perforaciones públicas a las que acuden los campesinos con bidones a fin de proveerse de agua; en situaciones críticas, toman el agua almacenada en las represas prediales a la que también acceden los animales. Como se observa, el agua que consumen los productores depende de una variedad de fuentes que, según el caso, pueden ser catalogadas como agua ASMI o ACMI.

\subsection{En el área urbana}

El agua administrada por la municipalidad proviene de las dos represas públicas que la captan del río La Mermela y de tres perforaciones; a diferencia de la que se envía por las acequias a los campos, la destinada al consumo en Chancaní se somete a un proceso de potabilización y llega a las casas del pueblo a través de una red convencional. Cuando se agota el vital líquido de las represas de captación se distribuye de las perforaciones con camiones cisterna. La que utilizan los pobladores de Chancaní es toda agua ACMI azul. A modo de síntesis, en la tabla 2 se presentan las estrategias implementadas por campesinos, productores capitalizados (ganaderos y agricultores) y pobladores de Chancaní para apropiarse del agua ASMI y ACMI en el área de estudio.

\subsection{Transformaciones socioproductivas}

Los cambios de uso de la tierra observados durante los últimos años están produciendo profundas transformaciones ecológicas y sociales. Las nuevas condiciones que impone el modelo agropecuario dominante en Argentina no sólo redefinen el perfil productivo de muchas regiones del país, sino también modifican la composición social y la relación de fuerzas existente entre actores sociales. La presencia creciente de productores capitalizados que desarrollan estrategias de producción e imponen reglas sociales muy distintas a las preexistentes imprimen al territorio una dinámica sin 


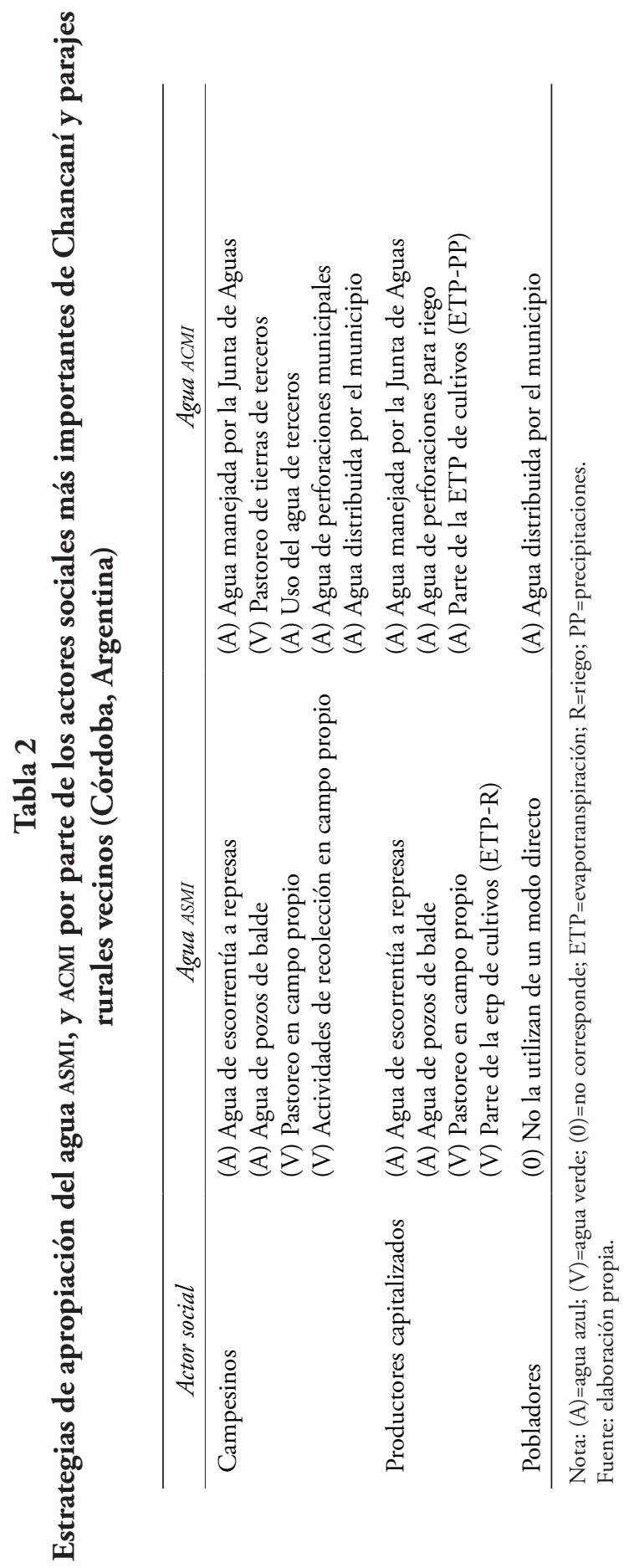


precedentes. Desde el punto de vista ecológico esto se traduce en un rápido cambio del paisaje regional y, desde el punto de vista social, en el creciente deterioro de las bases estructurales sobre las que se asientan las estrategias productivas campesinas.

Con relación a los objetivos que persigue esta investigación, cabe destacar tres aspectos principales: primero, está aumentando la importancia del agua ACMI en relación al agua ASMI; segundo, está ocurriendo una transferencia de agua desde los actores sociales más vulnerables hacia los más poderosos del territorio; y tercero, los conflictos por el agua disminuyen su visibilidad en el ámbito rural y se expresan con mayor claridad en espacios urbanos y periurbanos.

\subsubsection{De agua $A C M I$}

La crónica desatención de los campesinos por parte del Estado (ver sección 3.2.) sumada a las nuevas condiciones que impone la expansión de la producción agropecuaria empresarial ha debilitado la estructura productiva de las explotaciones campesinas; este deterioro se observa tanto en el plano social como en el productivo.

Desde el punto de vista social el elemento que ha producido el mayor impacto en la estructura y dinámica de las unidades campesinas ha sido el cambio en la cantidad y tipo de mano de obra disponible en las unidades campesinas. Esto se produce como consecuencia de los flujos migratorios que ocurrieron en la región durante la segunda mitad del siglo xx (Silvetti y Cáceres, 1998). En consecuencia se produjo una reducción en el número de miembros de la familia que permanecieron en la explotación, así como un cambio en la composición demográfica familiar: principalmente mujeres, niños y ancianos conservaron su residencia rural, mientras que los hombres jóvenes emigraron, lo cual produjo un fuerte impacto en las unidades campesinas ya que partieron los miembros de la familia con mayor capacidad para entregar trabajo a la explotación (Silvetti y Cáceres, 1998).

Esta importante pérdida en la cantidad y tipo de mano de obra tuvo un impacto notable en los sistemas campesinos, ya que su funcionamiento se basa fundamentalmente en tecnologías con baja productividad del trabajo. Si bien en algunos casos estas migraciones fueron temporarias o se revirtieron parcialmente, los cambios ocurridos produjeron el quiebre de sus estrategias productivas. Silvetti y Cáceres (1998) señalan que pasan de una estrategia productiva altamente diversificada que priorizaba el autoconsumo familiar, a otra donde la producción se concentra en unos pocos rubros destinados al mercado o al autoconsumo. 
La capricultura, por ejemplo, se adapta muy bien a las nuevas condiciones productivas ya que no demanda mucha mano de obra, se basa fundamentalmente en el trabajo femenino y aprovecha la participación de mano de obra marginal como niños y ancianos. También se produce un fuerte retraimiento (o incluso abandono) de las actividades agrícolas, ya que son las que mayor mano de obra demandan. Esto implica igualmente un deterioro de los aperos como los arados de mancera y rastras, la venta o no reposición de los animales de tiro, la interrupción del mantenimiento de los cercos de las chacras y el deterioro de la infraestructura predial, es decir, corrales, acequias, pozos de agua y represas.

Todo esto viene a la par de un proceso de erosión cultural donde se pierde gran parte del conocimiento vinculado con la diversificación productiva y la producción para el autoconsumo, lo que en conjunto representa una fuerte descapitalización económica, social y cultural de las explotaciones campesinas. Obviamente todos estos cambios no se producen solamente como consecuencia de la migración y de cuestiones que ocurren en el interior de los sistemas campesinos, sino también tienen que ver con la incipiente industrialización en la que se inserta Argentina, la fuerte atracción que ejercen las ciudades, la expansión y diversificación de los medios de comunicación, la mercantilización de las relaciones sociales y el menor compromiso del Estado con los campesinos.

Estos procesos impactan a los campesinos del área de estudio en sus estrategias de captación de agua ASMI azul, ya que tienen dificultades para realizar esta tarea porque no disponen de las herramientas o de la mano de obra necesaria para realizar un adecuado mantenimiento de sus represas. Debido a su situación económica, tampoco disponen de los recursos necesarios para contratar el servicio, lo cual no ocurre con los productores capitalizados, quienes disponen del capital necesario como para realizar un adecuado mantenimiento de represas.

La rápida expansión de la agricultura industrial bajo riego genera una demanda sin precedentes de agua ASMI subterránea. Las características y escala que alcanza actualmente la agricultura permiten que las napas freáticas se encuentren sujetas a una alta presión de extracción. Algunos productores que disponían de pozos de balde señalan que en los últimos años han disminuido su caudal o simplemente se han secado, lo que podría estar relacionado con la alta extracción de agua para riego. En cualquier caso, la realidad es que los pozos de balde entregan hoy menos agua ASMI que la que ofrecían anteriormente.

Los campesinos son quienes sufren con mayor intensidad este problema ya que no disponen de suficiente mano de obra o recursos económicos como para cavar más profundamente los pozos y, en consecuencia, comienzan a depender cada vez más de la provisión de agua ACMI ofreci- 
da por la Junta de Aguas (vía acequias) o de la municipalidad (vía camiones cisterna o perforaciones municipales). Por otro lado, se observan procesos de emigración parcial o total de las familias campesinas, lo que explica el marcado crecimiento de la población de Chancaní, y así, todas las personas que abandonan su residencia rural dejan de usar agua ASMI y pasan a depender exclusivamente del agua ACMI.

La creciente dependencia de agua ACMI implica también un progresivo proceso de mercantilización. El agua ASMI es gratis ya que, de acuerdo con la legislación vigente, quienes la utilizan no deben pagar ningún tipo de tributo o canon, lo cual no ocurre con el acceso a algunas de las fuentes de agua ACMI, ya que tanto el agua de red que distribuye la municipalidad de Chancaní como la distribuida por camiones cisterna tienen costos que deben afrontar los usuarios. Asimismo, el agua administrada por la Junta de Aguas y la obtenida en las perforaciones para riego agrícola están sujetas al pago de cánones específicos. Cabe destacar que, salvo el agua distribuida por los camiones, los montos que pagan quienes acceden a las otras fuentes de agua ACMI son bastante bajos. No obstante, e independientemente de cuánto paga cada uno, se observa una tendencia a la mercantilización del agua y al desarrollo de mercados específicos para su comercialización.

\subsubsection{Mayor inequidad en el acceso al agua}

$\mathrm{Al}$ igual que ocurre con la distribución de la tierra, el acceso al agua está regulado por las relaciones de poder dominantes en la sociedad (MeinzenDick y Nkonya, 2005). Este concepto es también válido para el área de estudio. No obstante, durante los últimos años se observa una inequidad creciente con respecto al acceso al agua, pues se favorece a los actores sociales más poderosos, en particular los productores empresariales.

Como se señala más arriba, la apropiación de agua Asmi por parte de los campesinos ha decrecido, ya que no pueden mantener en condiciones favorables sus represas y sus pozos de balde disminuyen o interrumpen su aporte de agua. Además, también tienen menor acceso al agua ACMI pues entran en crisis muchos de los acuerdos sociales que les permitían el acceso al agua verde o azul. Efectivamente, los cambios observados en el territorio en cuanto a condiciones productivas, y en especial la mayor presencia de un actor social con una lógica productiva distinta, es decir, los grandes productores, conspiran para que los campesinos puedan sostener el acceso a las tierras de pastoreo de terceros (agua ACMI verde) o las fuentes de agua de otros productores (agua ACMI azul). Incluso en algunos casos en los que los acuerdos se mantienen, en la práctica no se hace efectivos ya que los alambrados de las explotaciones empresariales limitan el 
desplazamiento del ganado. Por otro lado, los campesinos están incrementando su dependencia del agua ACMI que ofrece el municipio a través de las perforaciones públicas y de los camiones cisterna.

En contraste, los productores capitalizados logran una apropiación creciente del agua ya que tienen mejores condiciones para captar el agua ASMI y poseen mayor poder para negociar el acceso al agua ACMI destinada a fines productivos. Sin embargo, mantienen su acceso histórico al agua ASMI ya que tienen los recursos necesarios para realizar el mantenimiento de sus represas y dar mayor profundidad a los pozos de balde. Incluso, si lo creen conveniente, pueden aumentar el número de represas y pozos disponibles en sus predios. Por otro lado, tienen mayores posibilidades de acceder al agua ACMI azul que distribuye la Junta de Aguas, ya que su mayor poder los coloca en una buena posición para negociar. Incluso, a través de las perforaciones para riego, han desarrollado una nueva fuente de apropiación de agua azul, prácticamente inexistente hace unos ańos,aunque no disputan el acceso al agua ACMI que ofrece la municipalidad para consumo humano, ya que no la necesitan.

Si bien pueden existir casos particulares que no responden al patrón global, las transformaciones socioproductivas descritas permitirían identificar las tendencias generales que se resumen en la tabla 3.

Tabla 3

Cambios en la apropiación de agua ASMI y ACMI por parte de los principales actores sociales de Chancaní y parajes rurales vecinos (Córdoba, Argentina)

\begin{tabular}{|c|c|c|}
\hline Actor social & Agua ASMI & Agua ACMI \\
\hline Campesinos & $\begin{array}{l}(\downarrow) \text { Escorrentía a represas } \\
(\downarrow) \text { Agua de pozos de balde } \\
\text { (=) Pastoreo en campo propio } \\
\text { (=) Actividades de recolección } \\
\text { en campo propio }\end{array}$ & $\begin{array}{l}(\downarrow) \text { Agua manejada por la Junta } \\
\text { de Aguas } \\
(\downarrow) \text { Pastoreo de tierras de terceros } \\
(\downarrow) \text { Uso de agua de terceros } \\
(\uparrow) \text { Agua de perforaciones municipales } \\
(\uparrow) \text { Agua distribuida por el municipio }\end{array}$ \\
\hline $\begin{array}{l}\text { Productores } \\
\text { capitalizados }\end{array}$ & $\begin{array}{l}\text { (=) Escorrentía a represas } \\
\text { (=) Agua de pozos de balde } \\
\text { (=) Pastoreo en campo propio } \\
\text { (=) Parte de la ETP de cultivos } \\
\text { (ETP-R) }\end{array}$ & $\begin{array}{l}(\uparrow) \text { Agua manejada por la Junta } \\
\text { de Aguas } \\
(\uparrow) \text { Agua de perforaciones para riego } \\
(\uparrow) \text { Parte de la etp de cultivos } \\
(\text { ETP-PP) }\end{array}$ \\
\hline Pobladores & $\begin{array}{l}\text { (0) No la utilizan de un modo } \\
\text { directo }\end{array}$ & $(\uparrow)$ Agua distribuida por el municipio \\
\hline
\end{tabular}

Referencias, $(\downarrow)=$ apropiación decreciente; $(\uparrow)=$ apropiación creciente; $(=)=$ igual apropiación; $(0)=$ no corresponde; $\mathrm{ETP}=$ evapotranspiración; $\mathrm{R}=$ riego; $\mathrm{PP}=$ precipitaciones.

Fuente: Elaboración propia. 
Esta tabla nuestra las distintas áreas en las que se sugiere una creciente apropiación de agua por parte de los productores empresariales. Mientras los campesinos disminuyen el acceso a dos de las cuatro fuentes de agua ASMI, los productores capitalizados mantienen un acceso estable de los cuatro flujos que manejan. Con respecto al agua ACMI, la situación es aún más contrastante ya que los campesinos tienen menor acceso a las fuentes de agua productiva y aumentan su dependencia del agua para consumo humano. En cambio, los grandes productores incrementan su participación en todos los flujos de agua vinculados a su esfera de interés. Otro análisis que se desprende de las Tablas 2 y 3 se relaciona con los cambios observados en la apropiación de agua verde y azul. Las principales disputas se ubican en torno al agua azul. No existen cambios en cuanto a la apropiación de agua ASMI verde, pero sí un menor acceso campesino al agua ACMI verde. La fuerte apropiación de agua ACMI azul por parte de los productores empresariales es el cambio más importante observado, el cual se vincula con el uso de agua subterránea para riego.

\subsubsection{Urbanización del conflicto por el agua}

El proceso de transformación socioproductiva descrito, proporciona elementos para discutir el tipo, las características y la intensidad de los posibles conflictos emergentes con relación a la apropiación del agua. $\mathrm{Si}$ bien están muy directamente vinculadas entre sí, en principio se podrían analizar dos situaciones específicas: el ámbito rural y el espacio urbano y periurbano.

Campesinos y productores capitalizados tienen lógicas, tradiciones e intereses diferentes, así como una distinta comprensión de los procesos históricos y, probablemente, diversas expectativas en relación al futuro. También resulta evidente que los grandes productores se están expandiendo en el territorio a expensas de los campesinos y que concentran una mayor cuota de poder económico, social y político.

Esto hace que los grandes productores tengan mayor capacidad de negociación ante los distintos organismos que regulan el acceso al agua ACMI que se encuentra dentro de su esfera de interés. La disputa se sitúa principalmente en torno al agua canalizada a través de las represas públicas de Chancaní administrada por la Junta de Aguas y el acceso al agua subterránea cuyo uso lo reglamentan las leyes provinciales mencionadas. La primera se relaciona con las necesidades productivas vinculadas a la ganadería empresarial y, la segunda, con la agricultura intensiva. Se configuran así dos espacios de lucha, uno local y otro provincial; en ambos, los productores capitalizados presentan mayor capacidad para ejercer su 
poder y poner en juego su capacidad de influir en las decisiones de los responsables de distribuir el agua ACMI.

La tarea probablemente sea más sencilla en el ámbito local ya que la Junta de Aguas no es una institución consolidada y transparente y ni siquiera tiene un reglamento escrito que fije criterios y prioridades para distribuir el agua; incluso, se sospecha de corrupción al interior del organismo y de recibir favores y prebendas por parte de los más poderosos (Rodríguez-Bilella, 2011). Tal vez resulte más difícil llegar a las esferas de decisión provincial para atender los aspectos vinculados con el aprovechamiento del agua subterránea, pero en este caso, su forma de actuar pasa por desestimular o entorpecer los controles de los organismos pertinentes que procuran fijar normas restrictivas para el uso de agua freática. A diferencia de lo que ocurre con la movilización de intereses a escala local, en el ámbito provincial se valen de la capacidad de presión que ejercen a través de las organizaciones de productores, tales como la Sociedad Rural Argentina, Cartez y Federación Agraria Argentina, entre otras.

Así, la reciente sanción de la ley 9814 que regula el uso del suelo de la Provincia de Córdoba donde se impuso el proyecto impulsado por las organizaciones de productores empresariales por sobre el elaborado por las organizaciones campesinas, las ONG ambientalistas y las universidades, es un claro ejemplo del poder que acumula este actor social y su capacidad para influir en las esferas de decisión política provincial.

A este actor social se enfrentan los campesinos quienes, para lograr mayor visibilidad y alcanzar un mayor empoderamiento crearon, hace 10 años, la Unión de Campesinos de Traslasierra (Ucatras) que forma parte del Movimiento Campesino Cordobés. Dicha asociación aborda el problema de la injusta distribución de la tierra y el agua, y defiende el estilo de vida y la cultura campesina (Esteve, 2009) aunque, por ser una organización nueva, agrupa sólo una porción de los campesinos del territorio y su capacidad de agencia es restringida, sobre todo si se tiene en cuenta la magnitud y dimensión del proceso socioproductivo al que se enfrentan.

El resultado de la disputa va a depender de la capacidad de las organizaciones campesinas y sus aliados para construir poder, pero también de las características propias del proceso de penetración capitalista en la región. Los campesinos son sujetos resilientes que han demostrado gran flexibilidad y creatividad para readecuar sus estrategias y para sobreponerse a presiones externas; no obstante, estas capacidades operan dentro de ciertos límites que dependen de su fortaleza individual y social y de la naturaleza de los procesos de cambio que les toca enfrentar (Cáceres et al., 2010).

El acceso al agua por los pobladores de Chancaní no es independiente de lo que ocurre en el ámbito rural, ya que la principal fuente que 
abastece a quienes viven en el pueblo proviene de las represas públicas que administra la Junta de Aguas, la misma fluencia que los productores capitalizados disputan para destinar a la ganadería. Cabe recordar que ésta es una fuente bastante inaccesible pues canaliza el agua proveniente del río La Mermela y, debido al régimen pluviométrico, en primavera la disponibilidad de agua es mínima pues se registra la máxima demanda para fines productivos.

Durante los últimos años ha aumentado la preocupación de los pobladores de Chancaní por el abastecimiento de agua; el último conflicto importante ocurrió en diciembre de 2007, cuando la tardía llegada de las lluvias provocó que la provisión del agua potable entrara en una fase crítica. Si bien existen perforaciones que complementan el agua de las represas públicas, su caudal es insuficiente y el costo de extracción y distribución es elevado; además, no siempre están en condiciones de operar debido a problemas técnicos o prácticos. Es necesario destacar que quienes demandan el agua distribuida por camiones cisterna deben pagar un precio comparativamente alto. Así, desde el punto de vista de los habitantes de Chancaní, el agua administrada por la Junta de Aguas es la más confiable y barata, aunque su apropiación está sujeta a fuertes tensiones entre el uso rural y urbano.

La probable urbanización del conflicto por el agua no se vincula únicamente con el hecho de que la población de Chancaní haya crecido significativamente, pues indirectamente, esta situación afecta a muchos de los que todavía viven en áreas periurbanas y rurales y que, como consecuencia del proceso de transformación socioproductiva descrito, dependen cada vez menos de las actividades productivas rurales y cada vez más de las redes y servicios urbanos. Asimismo, existe la posibilidad de que algunos utilicen los conflictos y crisis que se generan en torno a la apropiación del agua para obtener beneficios privados, para desplegar sus redes clientelares o para acumular poder político. Este proceso podría alimentar una espiral creciente de inequidad en torno al acceso al agua y una mayor conflictividad en torno a su apropiación.

\section{Escenarios emergentes}

Observando las características del proceso y las trayectorias de los principales actores sociales, a continuación se construye un posible escenario futuro caracterizado por la tendencia a pasar por alto el conflicto por el agua en el ámbito rural, y la emergencia de mayores tensiones y enfrentamientos en el espacio urbano y periurbano.

El deterioro de las condiciones de reproducción social campesinas y las tracciones que genera la mayor disponibilidad de servicios y el estilo 
de vida urbano promueven el abandono de su residencia rural (parcial o total). ${ }^{2}$ Simultáneamente, aumenta la presencia de productores capitalizados que impulsan una lógica productiva y social que debilita las estrategias campesinas. De esta manera, las asimetrías en capital económico, político y social colocan a los empresarios en una mejor posición para apropiarse del agua ASMI y para negociar un mejor acceso al agua ACMI.

Ante ello, quizá la acción organizada sea la mejor alternativa de la que disponen los campesinos, tanto para mantener su acceso al agua ASMI, como para disputar el agua ACMI; sus posibilidades de éxito dependerán de la capacidad de agencia que muestre su organización y de las características e intensidad del proceso de penetración del capitalismo agrario en la región. Si se consolidan o amplían las asimetrías de poder existentes y si se sigue debilitando la trama social campesina puede ocurrir que las disputas no se manifiesten a través del enfrentamiento directo entre actores, sino a través de estrategias defensivas como las que describe Scott (1986) cuando hace referencia a las formas cotidianas de resistencia campesina.

Las características del proceso descrito no permiten suponer una reversión importante en el crecimiento demográfico de Chancaní, por lo que no es razonable esperar una reducción en la demanda de agua ACMI. Debido a que la fuente principal es bastante inaccesible, la menor disponibilidad de agua por habitante puede generar tensiones y conflictos, en particular, durante periodos críticos. Los campesinos que están emigrando a Chancaní, los que aún viven en el campo pero que dependen cada vez más de las redes sociales y servicios que allí se ofrecen, y los que siempre vivieron en el pueblo o en sus alrededores serán los principales damnificados; mientras que el intendente, otros referentes políticos de Chancaní y la Junta de Aguas serán los actores sociales a los que se enfrentarán los pobladores urbanos. Si bien existe directa relación entre la provisión de agua en Chancaní y la apropiación del agua que ejercen los productores capitalizados, estos difícilmente estarán en el centro de la disputa, ya que no viven en el pueblo y porque son veladas sus acciones para conseguir los favores de la Junta de Aguas.

\footnotetext{
${ }^{2}$ No es el objetivo de esta investigación analizar el problema de la persistencia o descomposición del campesinado. En líneas generales consideramos que su persistencia dependerá del interjuego de un conjunto de factores económicos, sociales y políticos, entre los que destacan (i) las características e intensidad de la penetración capitalista, (ii) la trayectoria de las unidades campesinas y sus organizaciones, y (iii) el rol que desempeńa el Estado como regulador y generador de políticas específicas para el sector. Cáceres et al. $(2010 ; 2011)$ analizan esta problemática para los campesinos del centro de Argentina.
} 


\section{Conclusiones}

Esta investigación propone nuevas conceptualizaciones que puedan ayudar a comprender mejor los procesos de producción y apropiación del agua. Se sugiere que el eje del debate no debería colocarse en la cantidad y calidad del agua fluida disponible, sino en la forma en que ésta es producida por los ecosistemas y apropiada por los distintos actores sociales.

El enfoque que aquí se presenta permite pasar de una posición conceptual en la que el eje estaba puesto en aspectos físico-biológicos, a otra en la que el énfasis se coloca en aspectos sociales y políticos, en particular, en las relaciones de poder y en las estrategias que desarrollan los distintos actores sociales que se disputan su apropiación. Desde esta perspectiva, comprender la dinámica del agua requiere considerar dos cuestiones: por un lado, la complejidad de los procesos ecosistémicos que, a su vez, están muy influenciados por las acciones que sobre ellos ejercen los grupos sociales a través de los distintos manejos y usos del suelo; por otro lado, el acceso al agua no se produce de un modo natural sino que está regido por las estrategias de apropiación que desarrollan cada uno de los actores sociales involucrados, y por la capacidad de los productores capitalizados para imponer sus reglas y sus prioridades de uso sobre los campesinos.

Estas disputas se zanjan a través de la construcción de acuerdos sociales, la sanción de normas y a la operación de instituciones (formales o informales) que son quienes en última instancia expresan la forma en que se dirimen las confrontaciones sociales y las relaciones de poder existentes entre los distintos actores sociales interesados en su apropiación.

La aplicación de estas conceptualizaciones a un caso específico en la Provincia de Córdoba permite observar que está aumentando la importancia relativa del agua ACMI, y que en el escenario emergente los conflictos por el agua probablemente tengan una expresión más clara en los ámbitos urbanos y periurbanos. La mayor dependencia del agua ACMI y la disparidad de poder que acumulan los distintos actores sociales generan un espacio propicio para que se agudicen las inequidades sociales o que se incrementen los conflictos por el acceso al agua.

El avance de la lógica económica que orienta la expansión del capitalismo agrario en áreas marginales debilita la autonomía campesina para acceder al agua necesaria y, de esta manera, alcanzar su reproducción social. Esto significa que se está precarizado el acceso al agua por parte de la población pobre de la región, tanto para fines productivos como para consumo humano. Así, de una situación de relativa autosuficiencia se pasa a otra caracterizada por una elevada dependencia externa, una atomización de la oferta de agua y una incipiente mercantilización. 
Por su parte, las instancias políticas que regulan el acceso al agua a nivel local no parecen estar comprometidas con la búsqueda de soluciones de fondo; con respecto al sector campesino, la municipalidad toma una postura asistencialista y focaliza su estrategia en la provisión de agua para consumo humano a través de perforaciones públicas o su distribución en camiones. El agua canalizada a través de las represas públicas es administrada por una Junta de Aguas poco transparente y de la que se sospecha que favorece los intereses de los más poderosos. Los productores capitalizados que impulsan nuevos abordajes productivos en la región logran imponer sus condiciones y están siendo los más exitosos en apropiarse del agua ACMI, lo cual incluye no sólo el agua manejada por la Junta de Aguas y destinada principalmente a la ganadería vacuna, sino también el agua subterránea utilizada para regar los cultivos intensivos.

La mayor dependencia por el agua ACMI de campesinos y pobladores pobres ofrecida por la municipalidad y la Junta de Aguas, consolida su posición subordinada y la inequidad social estructural propia de estas comunidades y, al mismo tiempo, aumenta la posibilidad de que sean objeto de prácticas clientelares o de sujeción política.

\section{Agradecimientos}

Nuestro reconocimiento a los productores, técnicos y funcionarios entrevistados durante el trabajo de campo, al Consejo Nacional de Investigaciones Científicas y Técnicas (Conicet), a la Universidad Nacional de Córdoba (UNC) y a la Universidad Nacional de San Juan (UNSJ). También agradecemos el apoyo financiero del Instituto Interamericano sobre el Cambio Global (IAI) CRN 2015 y sGP-CRA 2015, el que cuenta con el financiamiento de la us Nacional Science Foundation (grants GEO0452325 y GEO-1138881).

\section{Bibliografía}

Aizen, Marcelo A., Lucas A. Garibaldi y Mariana Dondo (2009), "Expansión de la soja y diversidad de la agricultura argentina”, Ecología Austral, 19, Asociación Argentina de Ecología, Buenos Aires, pp. 45-54.

Ameigeiras, Aldo Rubén (2007), "El abordaje etnográfico en la investigación social", en Irene Vasilachis de Gialdino (coord.), Estrategias de investigación cualitativa, Gedisa, Buenos Aires, pp. 107-152. 
Appendini, Kirsten y Monique Nuijten (2002), "El papel de las instituciones en contextos locales", Revista de la CEPAL, 76, Comisión Económica para América Latina y el Caribe, Santiago de Chile, pp. 71-88.

Auge, Miguel, Cristian Wetten, Guillermo Baudino, Guillermo Bonorino, Rubén Gianni, Nilda González, Mario Grizinik, Mario Hernández, José Rodríguez, Aldo Sisul, Alfredo Tineo y Carlos Torres (2006), "Hidrogeología de Argentina”, Boletín Geológico y Minero, 117 (1), Instituto Geológico y Minero de España, Madrid, pp. 7-23.

Bocco, Mónica, Rubén Coirini, Ulf Karlin y Axel von Müller (2007), "Evaluación socioeconómica de sistemas productivos sustentables en el Chaco Árido, Argentina”, Zonas Áridas, 11 (1), Centro de Investigaciones de Zonas Áridas, Lima, pp. 71-88.

Bravo, Ana Lucía (2010), “Introducción”, en Ana Lucía Bravo, Hugo Florencio Centurión-Mereles, Diego Ignacio Domínguez, Pablo Sabatino, Carla Mariela Poth y Javier Leonel Rodríguez, Los señores de la soja. La agricultura transgénica en América Latina, Centro de Integración, Comunicación, Cultura y Salud-Consejo Latinoamericano de Ciencias Sociales, Buenos Aires, pp. 9-30.

Britos, Andrés Horacio y Alicia Haydee Barchuk (2008), "Cambios en la cobertura y en el uso de la tierra en dos sitios del Chaco Árido del noroeste de Córdoba, Argentina”, AgriScientia, 25 (2), Universidad Nacional de Córdoba, Córdoba, pp. 97-110.

Bruns, Bryan Randolph y Ruth Meinzen-Dick (2005), "Frameworks for water rights: an overview of institutional options", en Bryan Randolph Bruns, Claudia Ringler y Ruth Meinzen-Dick, Water rights reform: lessons for institutional design, IFPRI, Washington, DC, pp. 3-26.

Cabido, Marcelo, Anibal Manzur, Laura Carranza y Carolina González Albarracín (1994), "The vegetation and physical environment of the Arid Chaco in the province of Córdoba, central Argentina", Phytocoenologia, 24, E. Schweizerbart Science Publishers, Stuttgart, pp. 423-460. 
Cabido, Marcelo, Marcelo R. Zak, Ana María Cingolani, Daniel Cáceres y Sandra Díaz (2005), "Cambios en la cobertura de la vegetación del centro de Argentina. ¿Factores directos o causas subyacentes?”, en Martín Oesterheld, Martín Aguiar, Claudio Ghersa y José María Paruelo (eds.), La heterogeneidad de la vegetación de los agroecosistemas, Universidad Nacional de Buenos Aires, Buenos Aires, pp. 271-300.

Cabrera, Ángel Lulio (1976), "Regiones fitogeográficas argentinas”, en Enciclopedia argentina de agricultura y ganadería, ACME, Buenos Aires, pp. 1-85.

Cáceres, Daniel M. (2003), "El campesinado contemporáneo en la República Argentina”, en Ricardo Thornton y Gustavo Cimadevilla (eds.), La extensión rural en debate. Concepciones, retrospectivas, cambios y estrategias para el Mercosur, INTA, Buenos Aires, pp. 173-197.

Cáceres, Daniel M., Gustavo Soto, Guillermo Ferrer, Felicitas Silvetti y Catalina Bisio (2010), "La expansión de la agricultura industrial en Argentina central: su impacto en las estrategias campesinas", Cuadernos de Desarrollo Rural, 7 (64), Pontificia Universidad Javeriana, Bogotá, pp. 91-119.

Cáceres, Daniel M., Felicitas Silvetti, Guillermo Ferrer, Gustavo Soto y Catalina Bisio (2011), "Los impactos de la agriculturización en el norte de Córdoba. Descampesinización y persistencia”, en Natalia López Castro y Guido Pividera, Repensar la agricultura familiar: aportes para desentrañar la complejidad agraria pampeana, Centro de Integración, Comunicación, Cultura y Salud, Buenos Aires, pp. 77-96.

Cáceres, Daniel M. (2014), "Accumulation by dispossession and socioenvironmental conflicts caused by the expansion of agribusiness in Argentina”, Journal of Agrarian Change, 14, Wiley, New Jersey, en prensa.

Calvo, Sonia Cecilia, María Laura Salvador, Claudio González Palau y Daniel Iglesias (2008), "Anexo 19: La cadena de carne bovina en la Provincia de Córdoba: implicancias para el desarrollo regional”, El balance de la economía Argentina 2008, Instituto de Investigaciones Económicas-Bolsa de Comercio, Córdoba, pp. 1-27. 
Cardona, Gabriela (2006), "Problemas ambientales y socioeconómicos asociados a las actuales formas de uso de la tierra en un área de la Región Chaqueña (Argentina)", Ecosistemas, 15 (3), Asociación Española de Ecología Terrestre, Mostoles, pp. 158-170.

Carranza, Carlos y Marcela Ledesma (2005), "Sistemas silvopastoriles en el Chaco Árido”, Revista IDIA XXI, IV (8), INTA, Buenos Aires, pp. 230-236.

Centurión-Mereles, Hugo Florencio (2010), “Avance de la agricultura transgénica. Impactos socioculturales y económicos en comunidades campesinas e indígenas del este paraguayo, entre la pervivencia y el ocaso", en Ana Lucía Bravo, Hugo Florencio Centurión-Mereles, Diego Ignacio Domínguez, Pablo Sabatino, Carla Mariela Poth y Javier Leonel Rodríguez, Los señores de la soja. La agricultura transgénica en América Latina, Centro de Integración, Comunicación, Cultura y Salud-Consejo Latinoamericano de Ciencias Sociales, Buenos Aires, pp.123-154

Cleaver, Frances y Tom Franks (2007), "New directions for water governance", ID 21 Inisights 67, IDs, Brighton, pp.1-2

Código de Aguas para la Provincia de Córdoba (2011), "ley 5589”, $<$ http://j.mp/u1rMy6>, diciembre de 2011.

Conti, Georgina (2011), "Efectos de la biodiversidad funcional sobre el almacenamiento de carbono bajo diferentes situaciones de uso de la tierra en el Chaco Seco, Argentina", tesis doctoral (en prep.), Universidad Nacional de Córdoba, Córdoba.

De Herdt, Tom, Johan Bastiaensen y Ben D’Exelle (2004), “Towards a local-socio-institutional analysis of anti-poverty interventions: a critical review of methods and researchers", Discussion paper 2004, 4, Institute of Development Policy and Management-University of Antwerp, Antwerp, pp. 1-56.

DIss (Instituto Danés para Estudios Internacionales) (2006), “Competencia por el agua: Entendiendo el conflicto y la cooperación en la gestión local del agua”, Instituto Danés para Estudios Internacionales, Copenhague. 
D’Odorico, Paolo, Francesco Laio, Amilcare Porporato, Luca Ridolfi, Andrea Rinaldo e Ignacio Rodriguez-Iturbe (2010), "Ecohidrology of terrestrial ecosystems", BioScience, 60 (11), American Institute of Biological Sciences, Washington, DC, pp. 898-907.

Domínguez, Diego Ignacio y Pablo Sabatino (2010), "La muerte que viene en el viento. La problemática de la contaminación por efecto de la agricultura transgénica en Argentina y Paraguay", en Ana Lucía Bravo, Hugo Florencio Centurión-Mereles, Diego Ignacio Domínguez, Pablo Sabatino, Carla Mariela Poth y Javier Leonel Rodríguez, Los señores de la soja. La agricultura transgénica en América Latina, Centro de Integración, Comunicación, Cultura y Salud-Consejo Latinoamericano de Ciencias Sociales, Buenos Aires, pp. 31-122.

Escobal, Javier y Carmen Ponce (2000), "Innovaciones en la lucha contra la pobreza rural en América Latina”, ponencia presentada en el Encuentro de Altos Directivos contra la Pobreza Rural, 27 y 28 de enero, Santiago de Chile.

Esteve, Marisol (2009), “Tierra y agua para poder producir y vivir: el Movimiento Campesino Cordobés", Revista Theomai, 20, Universidad Nacional de Quilmes, Quilmes, pp. 186-200.

Falkenmark, Malin (1997), "Society's interaction with the water cycle: a conceptual framework for a more holistic approach", Hydrological Sciences/Journal des Sciences Hydrologiques, 42 (4), Taylor \& Francis, London, pp. 451-466.

Falkenmark, Malin y Johan Rockström (2006), "The new blue and green water paradigm: breaking new ground for water resources planning and management", Journal of Water Resources Planning and Management, 132 (3), American Society of Civil Engineers, Reston, pp. 129-132.

Ferrer, Guillermo (2007), "La capricultura en el noroeste de Córdoba. Nuevos actores sociales y el proceso de innovación tecnológica", tesis doctoral, Universidad Nacional de Córdoba, Córdoba.

Ghida-Daza, Carlos y Carina Sánchez (2009), Zonas agroeconómicas homogéneas Córdoba, Instituto Nacional de Tecnología Agropecuaria, Buenos Aires. 
Gras, Carla (2009), "El nuevo empresariado agrario: sobre la construcción y los dilemas de sus organizaciones", en Carla Gras y Valeria Hernández, La Argentina rural. De la agricultura familiar a los agronegocios, Biblos, Buenos Aires, pp. 215-236.

Gras, Carla y Karina Bidaseca (2010), "Ruralidades en debate: mutaciones territoriales e identitarias en el corredor sojero santafesino", en Carla Gras y Karina Bidaseca, El mundo chacarero en tiempos de cambio. Herencia, territorio e identidad en los pueblos sojeros, Centro de Integración, Comunicación, Cultura y Salud, Buenos Aires, pp. 21-37.

Gudynas, Eduardo (2010), "Agropecuaria y nuevo extractivismo bajo los gobiernos progresistas de América del Sur", Territorios, 5, Instituto de Estudios Agrarios y Rurales, Tegucigalpa, pp. 37-54.

Hodgson, Stephen (2007), "Water rights: a prerequisite for effective water governance?”, ponencia presentada en la Conferencia ICID, 19 de octubre, Londres.

Hoff, Holger, Malin Falkenmark, Dieter Gerten, Line Gordon, Louise Karlberg y Johan Rockström (2010), "Greening the global water system”, Journal of Hidrology, 384 (3-4), Elsevier, Stuttgart, pp. 177-186.

INDEC (Instituto Nacional de Estadística y Censos) (2001), "Censo Nacional de Población y Vivienda”, Instituto Nacional de Estadísticas y Censos, Buenos Aires.

INDEC (Instituto Nacional de Estadística y Censos) (2003), “Censo Nacional Agropecuario: resultados preliminares”, Instituto Nacional de Estadísticas y Censos, Buenos Aires.

Jobbagy, Esteban G., Marcelo D. Nosetto, Celina S. Santoni y Germán Baldi (2008), "El desafío ecohidrológico de las transiciones entre sistemas leñosos y herbáceos en la llanura Chaco-Pampeana”, Ecología Austral, 18 (3), Asociación Argentina de Ecología, Buenos Aires, pp. 305-322.

MA (Millenium Assesment) (2003), Millenium ecosystem assesment. Ecosystems and human well-being: health synthesis, Island Press, Washington, DC. 
MA (Millenium Assesment) (2005), Millenium ecosystem assesment. ecosystems and human well-being: biodiversity synthesis, Island Press, Washington, DC.

Meinzen-Dick, Ruth y Leticia Nkonya (2005), "Understanding legal pluralism in water rights: lessons from Africa and Asia", ponencia presentada en la Conferencia International Workshop on African Water Laws: Plural Legislative Frameworks for Rural Water Management in Africa, 26-28 de enero, Johannesburgo.

Messer, Norman y Philip Townsley (2003), Local institutions and livelihoods: guidelines for analysis, Rural Development Division, FAO, Rome.

Montaña, Elma (2013), Escenarios de cambio ambiental global, escenarios de pobreza rural. Una mirada desde el territorio, Clacso, Buenos Aires.

Palau, Marielle y Regina Kretschmer (2004), "La 'guerra de la soja’ y el avance del neoliberalismo en el campo paraguayo", OSAL, 13, Clacso, Buenos Aires, pp. 105-115.

Palau-Viladesau, Tomás (2005), Capitalismo agrario y expulsión campesina. Avance del monocultivo de soja transgénica en el Paraguay, CIEDRA, Asunción.

Pérez-Carrera, Alejo, Carlos Hernán Moscuzza y Alicia Fernández-Cirelli (2008), "Efectos socioeconómicos y ambientales de la expansión agropecuaria. Estudio de caso: Santiago del Estero, Argentina”, Ecosistemas, 17 (1), Asociación Española de Ecología Terrestre, Mostoles, pp. 5-15.

Postel, Sandra L., Gretchen C. Daily y Paul R. Ehrlich (1996), "Human appropriation of renewable freshwater", Science, 271, The American Association for the Advancement of Science, Washington, DC, pp. 785-788.

Poverty-Environment Partnership (2006), "Linking poverty reduction and water management", <http://europeandcis.undp.org/ WaterWiki/images/c/c2/PEP_Water_Publication.pdf>, 15 de mayo de 2011. 
Reyna, Santiago M., Teresa M. Reyna, María Orso, Estela E. Reyna, María Lábaque y Clara Gómez (2006), Plan de Gestión de los Recursos Hidricos de la Provincia de Córdoba, I Congreso Internacional sobre Gestión y Tratamiento del Agua Córdoba, 26-28 de abril, Córdoba.

Robin, Marie-Monique (2008), El mundo según Monsanto, Península, Barcelona.

Rockström, Johan, Malin Falkenmark, Louise Karlberg, Holger Hoff, Stefanie Rost y Dieter Gerten (2009), "Future water availability for global food production: the potential of green water for increasing resilience to global change", Water Resources Research, W00A12, 45 (4), American Geophysical Union, Washington, DC, pp. $1-16$.

Rodríguez-Bilella, Pablo (2011), "Gobernanza y conflictos por el agua en territorios rurales pobres: estudio de caso en el oeste de Córdoba (Argentina)", en Omar Miranda, Estudios sociales del riego en la agricultura Argentina, Instituto Nacional de Tecnología Agropecuaria, Buenos Aires, pp 167-180.

Román, Marcela y María del Carmen González (2006), “Concentración de la producción. Estudios de caso en las provincias de Buenos Aires y Córdoba, Argentina”, Cuadernos de Desarrollo Rural, 57, Pontificia Universidad Javeriana, Bogotá, pp. 33-58.

Rubio, Blanca (2007), “'Hacia un nuevo orden agroalimentario energético mundial?”, Revista Interdisciplinaria de Estudios Agrarios, 26/27, Asociación de Historiadores Latinoamericanos y del Caribe, Buenos Aires, pp. 5-23.

Santoni, Celina S., Esteban G. Jobbagy y Sergio Contreras (2010), "Vadose zone transport in dry forests of Central Argentina: role of land use", Water Resources Research, 46, American Geophysical Union, Washington, DC, pp. 1-12.

Schejtman, Alexander (1975), "Elementos para una teoría de la economía campesina: pequeños productores campesinos de hacienda”, El Trimestre Económico, 42 (166), Fondo de Cultura Económica, México, pp. 487-512. 
Scott, James C. (1986), "Everyday forms of peasant resistance", Journal of Peasant Studies, 13 (2), Routledge, London, pp. 5-35.

Silvetti, Felicitas y Daniel Cáceres (1998), "Una perspectiva sociohistórica de las estrategias de reproducción social de pequeños productores del noroeste de Córdoba”, Debate Agrario, 28, Centro Peruano de Estudios Sociales, Lima, pp. 103-127.

Silvetti, Felicitas (2010), "Estrategias campesinas, construcción social del hábitat y representaciones sobre la provisión de servicios ecosistémicos en el Chaco Árido. Un análisis sociohistórico en el Departamento Pocho (Córdoba, Argentina)", tesis doctoral, Universidad Nacional de Córdoba, Córdoba.

Silvetti, Felicitas, Gustavo Soto, Daniel M. Cáceres y Diego Cabrol (2013), “¿Por qué la legislación no protege a los bosques nativos de Argentina? Conflictos socioambientales y políticas públicas en la Provincia de Córdoba”, Mundo Agrario, 13 (26), Universidad Nacional de la Plata, La Plata, pp. 1-21.

Svampa, Maristella y Mirta Antonelli (eds.) (2009), Minería transnacional, narrativas del desarrollo y resistencias sociales, Biblos, Buenos Aires.

Tapella, Esteban (2011), "El conflicto social en torno a la apropiación de servicios ecosistémicos en el oeste de la Provincia de Córdoba. La posición de los actores sociales más vulnerables", tesis doctoral (en prep.), Universidad Nacional de Córdoba, Córdoba.

Taylor, Steven J. y Robert Bogdan (2000), Introducción a los métodos cualitativos de investigación, Paidós, Barcelona.

Trigo, Eduardo y Eugenio Cap (2003), "The impact of the introduction of transgenic crops in argentinean agriculture", AgBioForum, 6 (3), University of Missouri-Columbia, Columbia, pp. 87-94.

Van Dam, Chris (2003), “Cambio tecnológico, concentración de la propiedad y desarrollo sostenible. Los efectos de la introducción del paquete soja-siembra directa en el umbral al Chaco", Debate Agrario, 35, Centro Peruano de Estudios Sociales, Lima, pp. 133-181. 
Vásquez, Juan B., Roberto A. Miatello y Marcelo E. Roqué (1979), Geografía física de la Provincia de Córdoba, Boldt, Córdoba.

Zak, Marcelo R., Marcelo Cabido, Daniel Cáceres y Sandra Díaz (2008), "What drives accelerated land cover change in central Argentina? Synergistic consequences of climatic, socio-economic and technological factors", Environmental Management, 42 (2), Oak Ridge National Laboratory, Oak Ridge, pp. 181-189.

Zarrilli, Adrián G. (2007), "Bosques y agricultura. Una mirada a los límites históricos de la sustentabilidad de los bosques argentinos en un contexto de la explotación capitalista en el siglo xx", en Noemí María Girbal-Blacha y Sonia Regina Mendonça, Cuestiones Agrarias en Argentina y Brasil, Prometeo, Buenos Aires, pp. 289-312.

Legislación citada:

Código de Aguas para la Provincia de Córdoba, ley 5589, <http://j.mp/ u1rMy6>, diciembre 2011.

Ley Orgánica de la Dirección de Agua y Saneamiento, ley provincial 8548, <http://j.mp/sOI3I3>, 15 de diciembre 2011.

Ley provincial 6604 sobre los Consorcios de Usuarios, <http://j.mp/ vUyzxR>, 15 diciembre de 2011.

Recibido: 15 de junio de 2011. Reenviado: 28 de diciembre de 2011. Reenviado: 14 de marzo de 2012. Aceptado: 3 de mayo de 2012.

Daniel M. Cáceres. Doctor en ciencias agropecuarias por la Universidad Nacional de Córdoba, Argentina. Es investigador del Consejo Nacional de Investigaciones Científicas y Técnicas y docente de la Universidad Nacional de Córdoba. Su línea de investigación actual comprende el análisis de los impactos de la agricultura industrial en regiones extrapampeanas de Argentina. Entre sus publicaciones más recientes destacan, en coautoría: "Los impactos de la agriculturización en el norte de Córdoba. Descampesinización y persistencia", en N. L. Castro y G. Pividera (eds.), Repensar la agricultura familiar: aportes para desentrañar la 
complejidad agraria pampeana, Centro de Integración, Comunicación, Cultura y Salud, Buenos Aires, pp. 77-96 (2011); en coautoría, "Environmental winners and losers in Argentina's soybean boom", en H. Tiessen y J.W. Stewart (eds.), Applying ecological knowledge to landuse decisions, SCOPE-IAI-IICA, São Paulo, pp. 65-72 (2009); en coautoría, "La expansión de la agricultura industrial en Argentina central. Su impacto en las estrategias campesinas", Cuadernos de Desarrollo Rural, 64, Pontificia Universidad Javeriana, Bogotá, pp. 91-119 (2010); "La sostenibilidad de explotaciones campesinas situadas en una reserva natural de Argentina central", Agrociencia, 43, Universidad de Concepción, Concepción, pp. 539-550 (2009).

Pablo Rodríguez-Bilella. Doctor en sociología por la Universidad de Sussex (Reino Unido). Es investigador del Consejo Nacional de Investigaciones Científicas y Técnicas y docente de la Universidad Nacional de San Juan. Su línea de investigación actual comprende la evaluación de políticas públicas y su vinculación con las teorías de la complejidad. Entre sus últimas publicaciones se pueden mencionar las siguientes: "Strengthening the evaluation of sustainable development interventions: inputs from a social interfaces analysis and livelihood research", Environmental Policy and Governance, (en prensa); en coautoría "Evaluación, valoración, negociación: reflexiones en camino hacia una cultura de la evaluación", Canadian Journal of Program Evaluation (en prensa); en coautoría, Transformaciones globales y territorios: experiencias y aprendizajes de desarrollo rural en Argentina, La Colmena, Buenos Aires (2008); en coautoría, "The effects of functional biodiversity on ecosystem processes, ecosystem services and sustainability: an interdisciplinary approach", Newsletter of the Global Land Project International Project Office, 3, CIC-IDP-University of Copenhagen, Copenhagen, pp. 28-31 (2008). 